\title{
Childhood Hearing Loss in the Developing World
}

\author{
Claudine Störbeck*
}

\section{Centre for Deaf Studies, University of the Witwatersrand, P.O. Box 72391, Parkview, 2122, South Africa}

\begin{abstract}
Globally, unidentified hearing loss is the largest and most significant childhood disability impacting on development. Of the babies born annually with hearing loss, $90 \%$ come from developing countries. Less than $2.5 \%$ of these babies will get hearing aids and less than $10 \%$ will ever have access to early intervention.

With the dearth of services available to this largely marginalized paediatric community, the EHDI pathway has been established with significant buy in from the World Bank, WHO and UNESCO. This paper will explore the EHDI pathway and how it is currently being implemented in the developing world.
\end{abstract}

Keywords: Universal newborn hearing screening, paediatric hearing loss, early hearing detection and intervention, developing countries, early intervention.

Childhood hearing loss is the most prevalent sensory disorder [1] often referred to as the silent epidemic [2, 3] with more than $90 \%$ of these babies residing in the developing world [4-6]. 'Developing' is defined by indices such as gross national income (GNI), degree of integration into the global financial system, life expectancy and literacy among others with 150 countries currently on this list [7]. With an estimated 7 billion people on earth, the large majority are born into developing nations [8].

Of the approximately 123 million babies that are born annually in developing countries, 737000 are born with a permanent congenital early-onset hearing loss (PCHL) [9, 10]. This translates into 6 per 1000 live births ${ }^{1}$ in developing countries as opposed to 2 per 1000 live births in developed countries [9, 11], however higher rates have been noted in various developing countries during a review of worldwide infant screening in 2008 (see Table 1).

\section{HEARING LOSS AND ITS IMPACT}

Hearing loss is the most frequently occurring birth defect [12] and the World Health Organisation (WHO) estimates that it is among the 20 leading causes of the global burden of disease, one of only four non-fatal conditions [2]. Future projections indicate hearing loss will be increasing in these rankings, estimated to become the 7th leading cause of the global burden of disease in 2030 , primarily due to a growing global

*Address corresponding to this author at the Centre for Deaf Studies, University of the Witwatersrand, P.O. Box 72391, Parkview, 2122, South Africa; Tel: +27-11-717-3750; Fax: +27-11-717-3751;

E-mail: Claudine.storbeck@gmail.com

${ }^{1}$ Some are reported as even higher e.g. 7.9/1000 births in Pakistan $[47,66]$. population with increasingly long life expectancies $[2,13]$.

Children may be either born with a hearing loss (a congenital hearing loss) or acquire it after birth. There are more than 400 syndromes, sequences and associations that include hearing loss as a major feature [14] accounting for up to $50 \%$ of infant hearing losses [15] (see Table 2 for the aetiological and risk factors).

A disabling hearing loss is usually described as one above 30 or $40 \mathrm{~dB}[2,16]$, however research and experience has shown that if it remains undetected all hearing loss (including minimal and unilateral hearing losses) can have detrimental consequences [17-20]. These consequences include delays in language development, cognitive development and socioemotional development [6, 21-24] which may result in persistent language delays of 2-4 years [25]. These delays then have far reaching ramifications for academic, employment and societal integration [25, 26], particularly in developing countries. In addition to the impact of hearing loss on the child, there is also an impact on the family [27-29] and larger community [30] with communities in developing countries attributing stigma for the hearing loss to supernatural causes [31] or ancestral punishment [16].

At a societal level Mohr et al. [32] have calculated that the economic impact of this burden of disease for the life span of a person with a hearing loss is $\$ 1$ million, highlighting the imperative to identify hearing losses as soon as possible.

\section{EARLY HEARING SCREENING AND DETECTION}

As early as the 1960's paediatric audiology and newborn screening were being pioneered in the USA,

๑ 2012 Lifescience Global 
Table 1: Rate of Permanent Congenital and early-onset Hearing Loss ${ }^{a}$ (PCEHL) in Developing Countries ${ }^{b}$ (adapted from Olusanya et al., 2008) $)^{c}$

\begin{tabular}{|c|c|c|c|}
\hline Country & Rate of PCEHL/1000 & Country & Rate of PCEHL/1000 \\
\hline \hline Brazil & $2.4^{\mathrm{d}}$ & Pakistan & 7.9 \\
\hline China & 2.8 & Philippines & 22.1 \\
\hline Cyprus & 1.19 & Qatar & 53.4 \\
\hline India & $5.0-5.6$ & Saudi Arabia & 1.8 \\
\hline Jordan & 13.7 & Slovakia & 1.5 \\
\hline Kuwait & 51.2 & South Africa & 1.3 \\
\hline Malaysia & $4.4-12.5$ & Taiwan & 67.1 \\
\hline Mexico & 1.6 & Thailand & 4.2 \\
\hline Nigeria & $5.3-28$ & Turkey & \\
\hline
\end{tabular}

${ }^{a}$ Most of these studies included children with unilateral and mild hearing losses (although a detailed breakdown was not given), the community-based study from Nigeria may have included a significant number of infants with postnatal hearing loss and studies from Qatar and Kuwait were reported from populations with high rates of consanguinity.

${ }^{\mathrm{b}}$ The current list of developing countries are published in the International Monetary Fund's World Economic Outlook Report, April 2012 [7].

${ }^{\circ}$ The data were collected from a systematic review of studies on infant hearing screening across the developing world since 1998.

${ }^{\mathrm{d}}$ One study indicated a prevalence of as high as 102.1/1000.

Table 2: Aetiological and Risk Factors for Congenital and Early-Onset Hearing Loss (Adapted from Olusanya, 2012)

\begin{tabular}{|c|c|}
\hline \multicolumn{2}{|c|}{ Aetiological and risk factors for congenital and early-onset hearing loss } \\
\hline \multicolumn{2}{|l|}{ Prenatal } \\
\hline Family history of deafness & Genetic: Non-Syndromic \\
\hline Consanguinity & Connexin 26 \\
\hline Genetic: Syndromic & Connexin 31 \\
\hline Treacher-Collins syndrome & Others \\
\hline \multicolumn{2}{|l|}{ Pendred syndrome } \\
\hline Jervell Lange-Nielsen syndrome & Edward Syndrome \\
\hline Alport Syndrome & Patau Syndrome \\
\hline Hunter Syndrome & Turner Syndrome \\
\hline \multicolumn{2}{|l|}{ Cranionfacial anomalies associated with } \\
\hline Crouzon disease, Flippel-Feil syndrome, & Acquired Congenital Infections \\
\hline Goldenhar syndrome \& Pierre Robin Sequence & Maternal Rubella \\
\hline Other & Syphilis \\
\hline \multirow[t]{2}{*}{ Charge Association } & Congenital Malaria \\
\hline & Fetal Alcohol Syndrome \\
\hline \multicolumn{2}{|l|}{ Natal } \\
\hline Prolonged/obstructed labour & Hypoxia/ Birth Asphyxia \\
\hline Lack of skilled birth attendant & Low Apgar scores \\
\hline Mode of delivery & Prematurity/Low birth weight (<1500gr) \\
\hline Maternal hypertensive disorders in pregnancy & $\mathrm{NICU} /$ ventilation $>5$ days \\
\hline Maternal malnutrition in pregnancy & Trauma to the head \\
\hline Birth trauma & Maternal HIV infection \\
\hline \multicolumn{2}{|l|}{ Postnatal } \\
\hline
\end{tabular}


with the majority of the developed world following suite in the years to follow [33]. Internationally this has led to a strong move toward not only newborn screening, but universal newborn hearing screening (UNHS) where it is proposed that screening for hearing loss occur by no later than 1 month of age, diagnostics follow shortly thereafter to be finalized by three months of age and referral to early intervention to be in place by no later than six months of age [26]. This screening to intervention process is referred to as the 'early hearing detection and intervention' pathway (EHDI)

Screening protocols of the Joint Commission on Infant Hearing $(\mathrm{JClH})$ (used widely as a reference document) propose physiological measures using a 2stage screening protocol: an initial screening using an $\mathrm{OAE}^{2}$ (otoacoustic emissions test) followed by an automated ABR (automated brainstem response) if the first screen is not passed [26, 34, 35]. This is echoed by Olusanya [5] in a report on screening in Nigeria and McPherson and Olusanya [36] in discussion of screening in developing countries. In practice however, two studies in South Africa, one a national survey and the other a smaller geographically focused area, both reported on a one-stage screening protocol using predominantly OAE's alone with the rationale being one of ease and cost of screening [4, 37].

In the developed world the current protocol is that to a large extent they follow UNHS (Universal Newborn Hearing Screening) with a $95 \%$ screening rate in the USA [38] and $99 \%$ in the UK [39]. Yet more than 90\% of babies born in South Africa do not have the prospect of either screening or early detection [40] with an even lower prospect of identification in most other developing countries.

Screening in the developed world usually takes place in the hospital or clinic within a few days of birth and often before the child is discharged from the hospital. Less than $60 \%$ of babies born in developing countries are born in hospital [10] with numbers dropping to as low as $35 \%$ in South Africa and Nigeria, and $15 \%$ in Somalia among others [9]. This has led to various recommendations for community-based screening programmes to be offered in immunization clinics or Maternal and Child community clinics [4, 41].

Historically, screening and diagnostics have been performed by Audiologists and Ear Nose and Throat

${ }^{2}$ Protocols for equipment vary: TEOAEs were used in Nigeria while DPOAEs and AOAEs were used in the South African studies. surgeons (ENTs), however a recent survey of services within hearing health care in Africa revealed a severe shortage (or total lack) of ENT surgeons and Audiologists [42]. As opposed to the average ratio of audiologists to people in developed countries (1/20 $000)$, the ratio in developing countries ranges from $1 / 500000$ to as high as $1 / 6.25$ million $[13,43]$. Due to this dearth of hearing healthcare professionals, recommendations have been made to consider using nurses [4, 37, 44, 45] and other paraprofessionals in the screening of hearing loss [5, 46]. More recently recommendations have been made to consider telehealth as offering opportunities to access the full spectrum of EHDI in underserved populations [13] without the on-site availability of an audiologist.

In addition to a lack of professionals in the field, developing countries have widespread resource constraints [45] that they are going to need to adapt to. Fagan \& Jacobs (pg 7) propose a "lower technology, lower cost developing world medical practice" [42] and to this end the Joint Commission on Infant Hearing $(\mathrm{JCIH})$ and Olusanya $[5,45]$ have recommended that rather than universal newborn hearing screening (NHS), developing countries implement targeted newborn hearing screening (TNHS). This would include many of the high risk factors noted in Table 2, as well as some sites also requiring a bilateral refer, thus excluding any unilateral refers at screening.

Ideally, those infants with unilateral refers or bilateral passes with risk factors for hearing loss should be monitored in terms of their language development and milestone achievements on a 6-monthly basis [4, $26]$ in order to identify the children who either acquire or have late onset hearing loss.

In terms of this first phase of the EHDI pathway there are currently no benchmarks for evaluating infant hearing screening in developing countries, though all the pilot studies that have been done to date have made use of the $\mathrm{JCIH}$ guidelines [47]. Proposals have been made for developing countries to make use of targeted screening [4, 5, 34, 45], and that despite cost effectiveness and resource constraints withholding newborn hearing screening could not be justified for any population, but rather that context specific strategies be sought [9].

Once identified the EHDI pathway leads toward intervention and Young and Tattersal [28] state that "early identification is of little importance if it is not combined with quality services that can realize for 
children and families the potential advantage of significantly earlier diagnosis than had previously been the case" (p 209).

\section{EARLY INTERVENTION}

The process of early intervention includes amplification, therapeutic intervention as well as holistic child and family-centred early intervention. As with screening and diagnosis, it is acknowledged that the referral to intervention also needs to occur as early and as swiftly as possible [26]. Based on current research in developing countries it appears that beyond the primary focus of preventing or detecting hearing loss early [48], this is the component of the EHDI pathway that is most lacking.

The benefits of early intervention are extolled internationally [49-52] though currently in the developing world the primary focus is on amplification [53].

The Convention on the Rights of Persons with Disabilities recognizes that access to assistive technology such as hearing aids is a basic right for persons with hearing impairment [54]. The World Health Organization estimates that fewer than 1 in every 40 people (less than 2.5\%) who could benefit from hearing aids actually receive this device $[2,55]$. This was confirmed through a survey of 18 African countries in which 9 reported that they had no access to hearing aids, 7 said their access was poor and only 2 said they had good access to hearing aid services [42]. In contrast one longitudinal study $(n=615)$ found that $94.5 \%$ of the infants were amplified ${ }^{3}$. Some of the challenges that developing countries experience with amplification include: affordability of the hearing aids, earmoulds and batteries [53], a chronic shortage of professionals to either assess hearing or provide the rehabilitative services [43], lack of awareness and tropical climates that impact on life-term of the hearing aid [55].

In terms of affordability, the WHO has established a guideline of affordability to ensure that hearing aids don't cost more that 3\% of gross national product (GNP) per capita [53]. Using this affordability guideline, this would translate to a costing range of 'equitable' prices from the USA $(\$ 1390)$ to China $(\$ 110)$ to Ethiopia (\$10) [55], however, this seems hard for the

\footnotetext{
${ }^{3}$ This research is from an unpublished annual report on an early intervention programme in South Africa [67].
}

manufacturers to reach, making hearing aids largely unaffordable to the developing world. Subsequently, local manufacturers are producing low-cost hearing aids in China and India for example [55] and where possible loaner hearing aid banks could be used [56]. In order to cut costs for earmoulds, Brouillette [53] proposes that in developing countries earmoulds need not only be custom made two-stage moulds, but that the stock ear canal tip be used (currently as many as $60 \%$ of hearing aid wearers in the least developed countries prefer these) or the one-stage 'instant' earmould (particularly for a severe to profound hearing loss). And finally the long-term cost of hearing aids batteries can be averted through either low-cost rechargeable batteries or using solar powered hearing aids (see discussion of Godisa in Brouilette, 2008). In order to overcome the shortage of access to professionals during the amplification process, Swanepoel et al. [13] propose making use of telehealth (see Table 3) which would make professional services more accessible through either synchronous or asynchronous support. Finally, awareness campaigns on hearing loss and the benefit of amplification need to be run [53] as well as an exploration of the possibility of weather proofing hearing aids for more tropical climates [55].

While effective amplification is an essential component of post identification intervention, Yoshinago-Itano \& Thomson [56] (pg 20) urge the sector "not wait to provide intervention service until hearing aids have been acquired" and that the primary objective of early intervention is access to communication, whether auditory or visual. In addition to communication, early intervention has as its goal to "meet the developmental needs of the child and the needs of their family related to enhancing the child's development" [57]. Effective early intervention is holistic and multifaceted [25, 26, 34, 58] as well as family-centred [25, 59]. Internationally, early intervention is often home-based [59], is totally unbiased and embraces informed choice $[60,61]$ as it relates to the gamut of choices parents need to consider (from amplification to language to modality to schooling among others).

In two studies on this second phase of the EHDI pathway the average age of identification was 24 months $(n=54)$ [62] and 31 months $(n=20)^{4}$ with age of

${ }^{4}$ Venter, C \& Viljoen, J. 2008. Children with hearing loss: Parental needs
regarding diagnosis. Unpublished B.Communication Pathology research report, regarding diagnosis. Unpublish
University of Pretoria, Pretoria. 
Table 3: Scope of Application Possibilities for Telehealth in Early Intervention (Adapted from Swanepoel et al., 2010)

\begin{tabular}{|c|c|c|}
\hline Field of application & Scope & th applications \\
\hline Intervention [65] & Synchronous & Asynchronous \\
\hline Counseling [65] & $\begin{array}{l}\text { Counseling and troubleshooting } \\
\text { conducted via interactive } \\
\text { videoconferencing }\end{array}$ & $\begin{array}{l}\text { Counseling sessions via interactive } \\
\text { videoconferencing may be preceded by } \\
\text { questions and complaints emailed }\end{array}$ \\
\hline Ear canal management & $\begin{array}{l}\text { Ear canal management guided remotely } \\
\text { by audiologist via videoconferencing }\end{array}$ & $\begin{array}{l}\text { Internet-based audiological counseling } \\
\text { programs } \\
\text { Internet-based audiological treatment } \\
\text { programs (i.e. tinnitus) }\end{array}$ \\
\hline $\begin{array}{l}\text { Hearing aid selection, fitting \& } \\
\text { verification }\end{array}$ & $\begin{array}{l}\text { Hearing aids fitting guided and } \\
\text { programmed via interactive } \\
\text { videoconferencing and application } \\
\text { sharing } \\
\text { Verification of hearing aid via } \\
\text { application sharing and interactive } \\
\text { videoconferencing }\end{array}$ & $\begin{array}{l}\text { Hearing aids may be pre-selected and } \\
\text { pre-programmed based on audiological } \\
\text { results }\end{array}$ \\
\hline Cochlear implant mapping & $\begin{array}{l}\text { Cochlear implant activation and } \\
\text { mapping via application sharing and } \\
\text { interactive videoconferencing }\end{array}$ & $\begin{array}{l}\text { Internet-based auditory training } \\
\text { programs }\end{array}$ \\
\hline Early Intervention & $\begin{array}{l}\text { Follow-up sessions via interactive } \\
\text { videoconferencing } \\
\text { Home-based early intervention services } \\
\text { via interactive videoconferencing }\end{array}$ & $\begin{array}{l}\text { Intervention for infants may be provided } \\
\text { by recorded play/ child communication } \\
\text { sessions at home sent through to } \\
\text { interventionist for evaluation } \\
\text { Home-visit sessions are preceded by questions } \\
\text { emailed } \\
\text { Internet-based early intervention topics }\end{array}$ \\
\hline
\end{tabular}

${ }^{a}$ Usually involves a paraprofessional or trained volunteer to facilitate the telemedicine setup at the remote location whilst the health care provider (audiologist) is present remotely via interactive videoconferencing.

referral to centre-based early intervention at 31 months and 43 months respectively (indicating a referral to intervention gap of between 8-12 months). A third longitudinal study of 615 infants revealed an average age of diagnosis of 26 months and referral to a homebased early intervention programme at 40 months, indicating a gap of over 12 months from identification to intervention (see footnote c). No further early intervention programmes could be located in the developing country research, however this does not necessarily mean there are no large-scale early intervention programmes in the developing world, but that the programmes are not yet documented.

\section{CONCLUSION}

All children with significant hearing loss have the basic human right to have access to human communication, regardless of where they are born, of their race, ethnicity or national origin, of how much income their family makes, the level of education of their parents, or the type of occupation (pg 1) [56]. To this end, developing countries need to ensure that this basic human right is acknowledged and prioritized by linking the implementation of such EHDI programmes to existing health, social and educational systems and where possible setting up private-public partnerships to enable the implementation [45].

There is widespread agreement that the golden standard to which developing countries should aspire in setting up EHDI processes is UNHS using physiological measures (OAE and $A B R$ ). Due to unique local challenges and resource constraints, however each small step toward the goal would be a valuable interim measure: whether starting with a geographical subset of infants (eg. a hospital or a clinic in a specific area) and working toward NICU, high risk and then national screening of babies or whether starting with family questionnaires and working toward behavioural and then physiological screening [63].

As the developing world looks ahead to putting national plans in place (WHA, 1995), time and energy needs to be invested into establishing national infrastructures that will ensure that each infant identified with a hearing loss (and their families) receives appropriate intervention services [56], as investing in early childhood will bring about important economic returns later in life [64]. 


\section{REFERENCES}

[1] Olusanya BO, Somefun AO, Swanepoel D. The need for standardization of methods for worldwide infant hearing screening: A systematic review. Laryngoscope 2008; 188: 1830-36.

[2] World Health Organisation. Deafness and hearing impairment. 2008; Available at: http://www.who.int/mediacentre/factsheets/fs300/en/ index.html. Accessed August 25, 2012.

[3] Swanepoel DW. Early intervention for hearing loss in South Africa: Cost benefits and current status. Ndiyeva Audiology Conference 2008.

[4] Friderichs N, Swanepeol DW, Hall J. Efficacy of a community based infant hearing screening programme utilising existing clinical personnel in Western Cape, South Africa. Int $\mathrm{J}$ Pediatr Otorhinolaryngol 2012; 76(4): 552-59.

[5] Olusanya BO, Emokpae A, Renner JK, Wirz SL. Costs and performance of early hearing detection programmes in Lagos, Nigeria. R Soc Trop Med Hyg 2009; 103: 179-86.

[6] Swanepoel DW, Störbeck C. EHDI Africa: Advocating for infants with hearing loss in Africa. Int J Audiol 2008; 47(Suppl 1): S1-S2.

[7] International Monetary Fund (IMF). World economic outlook: Growth resuming, dangers remain [Report on the internet]. IMF; 2012 [cited 2012 Sept 10]: Available from: http://www.imf.org/external/pubs/ft/weo/2012/01/pdf/text.pdf

[8] United Nations Population Fund (UNFPA). Delivering results in a world of 7 billion: 2011 Annual Report [Report on the internet]. UNFPA; 2012 [cited 2012 Sept 10]: Available from: http://www.unfpa.org/webdav/site/global/shared/documents/p ublications/2012/16434\%20UNFPA\%20AR_FINAL_Ev11.pdf

[9] Olusanya BO. Neonatal hearing screening and intervention in resource limited settings: an overview. Arch Dis Child $2012 ; 1-6$.

[10] United Nations Children's Fund (UNICEF). The state of the world's children. New York, NY: UNICEF 2011.

[11] Olusanya BO, Newton VE. Global burden of childhood hearing impairment and disease control priorities for developing countries. Lancet 2007; 369(9569): 1314-17.

[12] Hollenbeck L. Advocating for universal newborn hearing screening. Creative Nursing 2008; 14(2): 75-81.

[13] Swanepoel D, Clark JL, Koekemoer D, et al. Telehealth in audiology: The need and potential to reach underserved communities. Int J Audiol 2010; 49: 95-201.

[14] Nelson C. Young children with syndromes and other medical conditions. In: Watkins S, Taylor DJ, Pittman P, editors. SKI HI Curriculum. Volume 1. Logan, UT: Hope Inc 2004; pp. 1097-1118.

[15] Kenneson A, Van Naarden BK, Boyle C. GJB2 (Connexin 26) variants and nonsyndromic sensorineural hearing loss: a HuGE review. Genet Med 2002; 4(4): 258-74.

[16] Swanepoel D, Almec N. Maternal views on infant hearing loss and early intervention in a South African community. Int J Audiol 2008; 47(Suppl 1): S44-S48.

[17] Winston C. Young Children with minimal, mild, unilateral and conductive hearing losses. In: Watkins S, Taylor DJ, Pittman P, editors. SKI HI Curriculum. Volume 1. Logan, UT: Hope Inc 2004; pp. 1043-1096.

[18] Kaderavek JN, Pakulski LA. Minimal hearing loss is not minimal. Teaching exceptional children 2002; 34(6): 14-18.

[19] Davis JM, Ed. Our forgotten children: Hard of hearing pupils in the schools. Bethesda, MD: SHHH Publications 2001.

[20] Candlish PAM. Not deaf enough: Raising a child who is hard of hearing with hugs, humor and imagination. Washington DC: Alexander Graham Belll Association for the deaf 1996.
[21] Kennedy C, McCann D, Campbell MJ, Kimm L, Thornton R. Universal newborn screening for permanent childhood hearing impairment: an 8 year follow-up of a control trial. Lancet 2005; 355: 660-62.

[22] Yoshinaga-Itano C. Levels of evidence: Universal newborn hearing screening (UNHS) and early hearing detection and intervention systems (EHDI). J Commun Disord 2004; 37: 451-65.

[23] Storbeck C, Pittman P. Early Intervention in South Africa: Moving beyond hearing screening. Int J Audiol 2008; 47(Suppl 1): S36-S37-S43.

[24] Morton CC, Nance WE. Newborn hearing screening - a silent revolution. N Engl J Med 2006; 354: 2151-64.

[25] Yoshinaga-Itano C, Sedey A, Coulter DK, Mehl AL. Language of early- and later-identified children with hearing loss. Pediatrics 1998; 102: 1161-1162-1171.

[26] Joint Committee on Infant Hearing (JCIH). Joint Committee on Infant Hearing Year 2007 Position Statement: Principles and guidelines for early hearing detection and intervention. Pediatrics 2007; 120: 898-921.

[27] Global coalition of parents of children who are deaf and hard of hearing (GPOD). Position statement and recommendations for family support in the development of newborn hearing screening systems and early hearing detection and intervention systems worldwide [Position statement on the internet]. GPOD; 2010 [cited 2012 Sept 10]: Available from https://sites.google.com/site/gpodhh/Home/position_stateme nt

[28] Young A, Tattersall $H$. Universal newborn hearing screening and early identification of deafness: Parents responses to knowing early and their expectations of child communication development. J Deaf Stud Deaf Educ 2007; 12(2): 209-20.

[29] Young A. The impact of a cultural-linguistic model of deafness on hearing parents' adjustment to a deaf child. J Soc Work Pract 1999; 13: 172-75.

[30] World Health Organisation (WHO). Primary ear and hearing care training manuals. WHO; 2006 [cited 2012 Sept 10] Available from: http://www.who.int/pbd/deafness/activities/ hearing_care/en/index.html

[31] Andrade V, Ross E. Beliefs and practices of Black South African traditional healers regarding hearing impairment. Int $J$ Audiol 2005; 44: 489-99.

[32] Mohr PE, Feldman JJ, Dunbar JL, et al. The Societal costs of severe to profound hearing loss in the United States. Int $\mathrm{J}$ Technol Assess 2000; 16: 1120-35.

[33] Theunissen M, Swanepoel DW. Early hearing detection and intervention services in the public health sector in South Africa. Int J Audiol 2008; 47(Suppl 1): S23-S29.

[34] Health Professional Council of South Africa (HPCSA). Professional board for speech, language and hearing profession: Early hearing detection and intervention programmes in South Africa Position Statement. Pretoria: HPCSA 2007.

[35] Gauteng Department of Health and Social Services. Gauteng provincial neonatal and infant hearing screening clinical guideline for use in the public sector. Johannesburg: Gauteng Department of Health and Social Services 2011.

[36] McPherson B, Olusanya BO. Screening for hearing loss in developing countries. In: McPherson B, Brouilette R, editors. Audiology in developing countries. New York: Nova Science Publishers 2008; pp. 75-105.

[37] Meyer EM, Swanepoel D. Newborn hearing screening in the private health sector - a national survey. S Afr Med J 2011; 101(9): 665-67.

[38] Russ SA, White K, Dougherty D, Forsman I. Preface: Newborn hearing screening in the United States: Historical 
perspectives and future directions. Pediatrics 2010; 126: S3S6.

[39] National Health System. NHS Newborn Hearing Screening Programme: 2010-11 Annual Report and 2009-10 Data Report. London: NHS 2011.

[40] Swanepoel DW, Storbeck C, Friedland P. Early hearing detection and intervention in South Africa. Int $\mathrm{J}$ Pediatr Otorhinolaryngol 2009; 73(6): 783-86.

[41] Swanepeol DW, Louw B, Hugo R. A novel service delivery model for infant hearing screening in developing countries. Int J Audiol 2007; 46: 321-27.

[42] Fagan JJ, Jacobs M. Survey of ENT services in Africa: need for a comprehensive intervention. Global Health Action 2009; 1-7.

[43] Goulios H, Patuzzi RB. Audiology education and practice from an international perspective. Int J Audiol 2008; 46(4): 647-64.

[44] Moodley S, Storbeck C. The role of the neonatal nurse in early hearing detection and intervention in South Africa. Prof Nurs Today 2012; 16(4): 28-31.

[45] Olusanya BO. Making targeted screening for infant hearing loss an effective option in less developed countries. Int $\mathrm{J}$ Pediatr Otorhinolaryngol 2011; 75: 316-21.

[46] Arehart KH, Yoshinaga-Itano C, Thomson V, Gabbard SA, Stredler Brown A. The status of universal newborn hearing screening, assessment, and intervention systems in 16 states. Am J Audiol 1998; 7: 101-14.

[47] Olusanya BO, Swanepoel D, Chapchap MJ, et al. Progress toward early detection services for infants with hearing loss in developing countries. BMC Health Serv Res 2007; 7: 14-28.

[48] World Health Organisation (WHO). Preventing chronic diseases - a vital investment [Report on the internet]. WHO; 2005 [cited 10 September]: Available from: http://www.who.int/chp/chronic_disease_report/en/

[49] Moeller MP. Early intervention and language development in children who are deaf and hard of hearing. Pediatrics 2000; 106(3): E43.

[50] Yoshinaga-Itano C. From Screening to early identification and intervention: Discovering predictors to successful outcomes for children with significant hearing loss. J Deaf Stud Deaf Educ 2003; 8(1): 11-12-30.

[51] Guralnick MJ. Why early intervention works: A systems perspective. Infant Young Child 2011; 24(1): 6-28.

[52] Marschark M. Language development in children who are deaf: A research synthesis. Alexandria, VA: Project FORUM at National Association of State Directors of Special Education 2001.
[53] Brouillette R. Rehabilitation of hearing loss: challenges and opportunities in developing countries. In: McPherson B, Brouilette R, editors. Audiology in Developing Countries New York: Nova Science Publishers 2008; pp. 141-153.

[54] Borg J, Lindstrom A, Larsson S. Assistive technology in developing countries: National and international responsibilities to implement the Convention on the Rights of Persons with Disabilities. Lancet 2009; 374: 1863-65.

[55] McPherson B. Innovative technology in hearing instruments: Matching needs in the developing world. Trends in Amplif 2011; 15(4): 209-14

[56] Yoshinaga-Itano $C$, Thomson V. The work of the village: Creating a new world for children with hearing loss and their families. Int J of Audiol 2008; 47(Suppl 1): S14-S22.

[57] Carpenter B. The impetus for family-centred early childhood intervention. Child Care Hlth Dev 2007; 33(6): 664-69.

[58] Yoshinaga-Itano $\mathrm{C}$, Arehart $\mathrm{KH}$. The role of educators of the deaf in the early identification of hearing loss. Am Ann Deaf 1999; 144: 19-23.

[59] Watkins S, Taylor DJ, Pittman P, eds. SKI HI Curriculum. Logan, UT: Hope Incorporated 2004.

[60] American Speech-Language Hearing Association. Guidelines for audiologists providing informational and adjustment counseling to families of infants and young children with hearing loss birth to five years of age. Rockville, MD: ASHA 2008.

[61] Young A, Carr G, Hunt R, McCracken W, Skipp A, Tattersall $\mathrm{H}$. Informed choice and deaf Children: Underpinning concepts and enduring challenges. J Deaf Stud Deaf Educ 2006; 11(3): 322-36.

[62] van der Spuy T, Pottas L. Infant hearing loss in South Africa: Age of intervention and parental needs for support. Int $\mathrm{J}$ Audiol 2008; 47: S30-S35.

[63] World Health Organisation (WHO). Deafness and hearing impairment. Geneva: WHO 2010.

[64] World Bank. World Development Report 2006: Equity and Development [Report on the internet]. World Bank; 2005 [cited 2012 Sept 10]: Available from: http://siteresources.worldbank.org/INTWDR2006/Resources/ WDR on Equity_FinalOutline_July_public.pdf

[65] McCarthy M, Munoz K, White KR. Teleintervention for infants and young children who are deaf or hard of hearing. Pediatrics 2010; 126: S52-S58.

[66] Nagapoornima P, Ramesh A, Srilakshmi RS, et al. Universal hearing screening. Indian J Pediatr 2007; 74: 545-49.

[67] Storbeck C, Edley L, Moodley S. HI HOPES: 5 year review. 2012.

http://dx.doi.org/10.6000/1929-4247.2012.01.01.07

(C) 2012 Claudine Störbeck; Licensee Lifescience Global.

This is an open access article licensed under the terms of the Creative Commons Attribution Non-Commercial License (http://creativecommons.org/licenses/by-nc/3.0/) which permits unrestricted, non-commercial use, distribution and reproduction in any medium, provided the work is properly cited. 